\title{
Analgesic Efficiency of Tramadol Administered Prior to Hysteroscopy Procedure
}

\author{
Pınar KADİROĞULLARI', Kerem Doğa SEÇKİN', Burak YÜCEL ${ }^{1}$, Berna ASLAN ÇETİN', Sibel ARSLAN BARUT'1, \\ Gökhan YILDIRIM ${ }^{1}$
}

Istanbul, Turkey

\begin{abstract}
OBJECTIVE: In this study, our objective was to assess the pain scores using the Visual Analogue Scale (VAS) in patients who were given tramadol prior to office hysteroscopy in order to demonstrate its analgesic activity when given before this procedure.

STUDY DESIGN: This prospective study conducted in year 2015 included two group of patients undergoing office hysteroscopy that were defined on the basis of the type of analgesia. Patients in the first group (Group 1, $n=44$ ) received oral tramadol prior to the procedure, while patients in the other group (Group 2, n=44) received placebo. VAS scores were determined during (0 minutes) and after (15 minutes) the procedure.
\end{abstract}

RESULTS: There were no significant differences between groups in terms of age, parity and body mass index ( $p>0.05$ ). Comparison of VAS scores at 0 and 15 minutes, lower values were observed in tramadol patients at 0 minutes $(p<0.05)$, while scores at 15 minutes were not significantly different between the groups ( $p>0.05)$.

CONCLUSIONS: Although oral tramadol given prior to office hysteroscopy was effective and safe in reducing pain during the procedure, it is not useful for the pain that occurs after processing.

Keywords: Hysteroscopy, Oral tramadol, Visual analogue scale, Placebo

Gynecol Obstet Reprod Med 2016;22(3):152-155 DOI: 10.21613/GORM.2016.629

\section{Introduction}

Hysteroscopy represents the gold standard method for the assessment of the uterine cavity providing an effective means of evaluating patients with prolonged abnormal uterine bleeding as well as for histological sampling $(1,2,3)$.

Office hysteroscopy, on the other hand, offers the additional advantages of obviating the need for performing the procedure in the surgical theatre under general anaesthesia, shortening the procedure, and therefore reducing the risk and costs associated with this procedure performed to define uterine pathologies. However, the major limiting factor for the use

${ }^{1}$ Department of Obstetrics and Gynecology, Kanuni Sultan Süleyman Training and Research Hospital, Istanbul

Address of Correspondence: Pınar Kadiroğullar Kanuni Sultan Suleyman Training and Research Hospital, Department of Gynecology and Obstetrics, Istanbul, Turkey pinarsezer33@hotmail.com

Submitted for Publication: 28.06 .2016

Accepted for Publication: of office hysteroscopy is the discomfort caused by procedurerelated pain or low tolerance (4). Despite this, no pre-procedural analgesia is given to patients in most centres utilizing this method. Studies have suggested that approximately $35 \%$ of the patients undergoing office hysteroscopy without anaesthesia experience severe pain (5). The emergence of pain is usually a 2-step process involving the cervical dilatation and the dilation of the uterine cavity for advancing through the isthmus and placing the hysteroscopy device. Due to the abovementioned factors, many centres prefer to administer general anaesthesia to their office hysteroscopy patients. Several approaches such as analgesia or local anaesthesia have been used in an attempt to reduce the discomfort associated with hysteroscopy. Among these, orally administered mefenamic acid or dexketoprofen reduce the pain after hysteroscopy, although they fail to eliminate the discomfort occurring during the procedure $(2,6)$. Also, topical anaesthesia prior to hysteroscopy provided only limited benefits. While local administration of lignocaine gel or paracervical lignocaine anaesthesia is not suitable alternatives for reducing the pain during hysteroscopy $(8,9)$, trans-cervical injection of mepivacaine has been shown to reduce the pain during hysteroscopy (10). 
Tramadol is an opioid analgesic with central mechanism of action thought that to be produced by the release of serotonin and inhibition of the neural uptake of noradrenaline. Its analgesic effects usually start at 1 hour after administration, reaching a peak at 2 hours, and lasting nearly 4 to 8 hours (11). Tramadol is an opioid analgesic in which reduces probably pre-procedural anxiety and hence the pain perceived during the procedure. Tramadol is commonly utilized for the treatment of postoperative pain in gynaecology and obstetrics (12). Intravenous tramadol has been reported to be effective in reducing pain occurring during and after office hysteroscopy (13). However, the role of oral tramadol in reducing pain during office hysteroscopy has not been tested previously. Thus, this randomized, placebo controlled study was undertaken to assess the pain-reducing efficacy of oral tramadol during and after hysteroscopy.

\section{Material and Method}

This prospective study was undertaken in year 2015 at Kanuni Sultan Süleyman Research and Training Hospital with the participation of patients undergoing office hysteroscopy after institutional ethics committee approval and obtainment of written informed consent from the study subjects. Patient and control groups consisted of patients presenting with peri-menopausal abnormal uterine bleeding who had no previous history of surgery involving the uterus or cervix, except for caesarean section. There is no patient in menopause. Also, patients with chronic cardiac, renal, hematologic, or hepatic conditions or patients with regular use of medications that could potentially influence the efficacy of study drugs were excluded. Patients in study and control group were selected by randomized sampling. Office hysteroscopy procedures were performed at the same time of the day, at the same outpatient facility, and by the same operator, to the patients who were at follicular phase. On physical examination before the hysteroscopy procedure, patients were taken to the lithotomy position and speculum was performed. Tenaculum was not used and cervical dilatation was not performed for the procedure. Patients in Group 1 (study subjects, $\mathrm{n}=44$ ) received oral tramadol (Contramal, tramadol Hcl 100 mg tablets, Abdi İbrahim, Turkey) 1.5 hour before the procedure, while 44 patients in Group 2 (placebo subjects) received matched placebo tablets. The procedure was initiated 1.5 hour after ingestion of the tablets to coincide with the peak drug activity. A $5 \mathrm{~mm}$ thick flexible hysteroscope and a 30 degrees' optic lens (Karl Storz, Germany) were used for office hysteroscopy. Physiological saline was utilized to dilate the uterine distension. Pain during ( 0 minutes) and after (15 minutes) the procedure was graded using the Visual Analogue Scale (VAS), in which the pain is scored between 0 (no pain) and 10 (maximum possible pain) (Figure 1). VAS was administered to all patients by the same investigator. Data analysis was performed using SPSS Version 15.0. Median VAS scores between the groups were compared using MannWhitney $U$ test, while comparison of indications was done using Student's t test. A p value of less than 0.05 was considered significant.

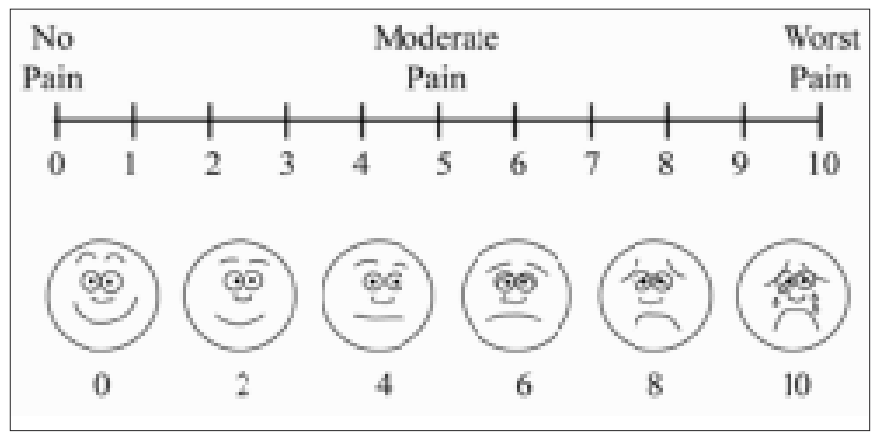

Figure 1: Visual analogue scale

\section{Results}

There were no significant differences between the groups in terms of mean \pm SD age (Group 1:45 \pm 1.4 years, Group 2: $44.08 \pm 1.3$ years), parity (Group 1: $2,1 \pm 1.06$, Group 2: 2.4 \pm 1.3 ) and body mass index (Group 1: $27 \pm 2.8 \mathrm{~kg} / \mathrm{m}^{2}$, Group $\left.2: 28.2 \pm 1.9 \mathrm{~kg} / \mathrm{m}^{2}\right)(\mathrm{p}>0.05)$. Also there were no significant differences in the proportion of patients with vaginal delivery or caesarean section ( $>0.05$ ). In both groups, abnormal uterine bleeding was the most frequent indication for hysteroscopy, and other indications were also similarly distributed across the groups ( $>0.05)$ (Table 1). No complications occurred during the procedures. A significantly lower VAS score in Group 1 (tramadol group) than in Group 2 (placebo group) was observed at 0 minutes $(p<0.05)$, while the difference at 15 minutes was not significant $(\mathrm{p}>0.05)$ (Table 2).

Table 1: Comparison of groups in terms of hysteroscopy indications

\begin{tabular}{lccc}
\hline Hysteroscopy indications & $\begin{array}{c}\text { Group 1 } \\
\text { (n:44) }\end{array}$ & $\begin{array}{c}\text { Group 2 } \\
(\mathrm{n}: 44)\end{array}$ & $\begin{array}{c}\mathrm{p} \\
\text { value }\end{array}$ \\
\hline Abnormal uterine bleeding & 15 & 19 & 0.08 \\
Endometrial polyp image in ultrasonography & 22 & 20 & 0.07 \\
Submucosal myoma image in ultrasonography & 7 & 5 & 0.09 \\
\hline
\end{tabular}


Table 2: Comparison of groups in terms of VAS scores during hysteroscopy

\begin{tabular}{l|c|c|c}
\hline & \multicolumn{2}{|c|}{ VAS scores } & \multicolumn{2}{c}{$\begin{array}{c}\text { Group 2 median } \\
(\mathrm{n}: 44)\end{array}$} & $\begin{array}{c}\mathrm{p} \\
\text { value }\end{array}$ \\
\hline Parameters & $\begin{array}{c}\text { Group 1 median } \\
(\mathrm{n}: 44)\end{array}$ & 5.9 & $\mathbf{0 . 0 3}$ \\
\hline 0.min & 3.6 & 5.4 & 0.09 \\
15.min & 5.1 & 5.4 \\
\hline
\end{tabular}

VAS: Visual analogue scale, min: minutes

\section{Discussion}

Despite the advantages of office hysteroscopy as a practical procedure that can be performed in the outpatient setting, its' use is limited mainly by the pain experienced by the patients. In this study, an agent with high analgesic efficacy and ease of administration, i.e. tramadol, was examined in terms of its ability to reduce pain in patients undergoing office hysteroscopy.

Previous reports have suggested inadequate analgesic efficacy for anaesthetic agents administered through a number of different ways including intra-cervical, para-cervical, and topical use. Also many randomized controlled studies examined the role of local anaesthesia in this indication. Local anaesthetic sprays have been shown to be an alternative approach for pain management during hysteroscopy and their major advantage involves the ease of use (14). Davies and colleagues compared lidocaine spray and placebo in 120 patients undergoing hysteroscopy and found an analgesic effect of lidocaine, particularly during the placement of the tenaculum, while this effect was lost in the later stages of the procedure with no significant difference from placebo and necessitating additional analgesia (15). Paracervical or intracervical block were also used for pain reduction (15), although block itself is a painful local anaesthetic procedure that may lead to increased risk of bleeding and intravasation, as shown by controlled studies (8). In a double blind placebo controlled study by Lau and colleagues, para-cervical block not only did not result in a decline in pain, but also could be associated with the development of complications such as bradycardia and hypotension (16). Broadbent and colleagues showed no pain reduction during hysteroscopy by intra-cervical lidocaine administration (17). Similarly, Johanson and colleagues could not detect an analgesic effect of para-cervical lidocaine during hysteroscopy (18). In another randomized controlled study, Vercellini and colleagues failed to detect analgesic efficacy of para-cervical anaesthesia during the most painful stage, i.e. endometrial biopsy sampling, of the procedure (9). Again, lidocaine gel applied to patients during diagnostic hysteroscopy did not result in pain reduction (8).

In Fritz et al.'s randomized, double blind, placebo controlled study, $500 \mathrm{mg}$ of mefenamic acid given 1 hour before hysteroscopy did not reduce the discomfort felt by the patient, while it was able to reduce the pain experienced after the procedure (2). Dogan et al. in their study where a combination of naproxen and lidocaine was used for pain management, a reduction of pain occurring during endometrial biopsy was observed (19). Mercorio et al. found no reduction of procedural discomfort, while pain after the procedure was reduced by dexketoprofen in their randomized controlled study (6).

In the randomized, controlled, double blind study by Floris et al. intravenous (iv) tramadol given 30 minutes prior to hysteroscopy was effective in reducing the discomfort during and pain after the procedure (13). Several previous case reports suggested that tramadol, an opioid analgesic, could be associated with abuse potential $(20,21,22)$. Also, in an experimental animal study by Cha et al. in 2014, repeated doses of tramadol was associated with psychological dependence in mice (23). In the present randomized, placebo controlled study, we investigated the analgesic efficacy of oral tramadol administered orally 1.5 hour prior to hysteroscopy on pain during and after the procedure. When compared for side effects and addiction potential oral tramadol versus iv administration, oral tramadol appears to be a good analgesic option for pain management during hysteroscopy.

Over time, hysteroscopy has evolved into a procedure that can be performed in the office setting thanks to the technological advances reducing the need for anaesthesia and analgesia during cervical dilatation in diagnostic or operative hysteroscopy. A number of different approaches including local anaesthetic sprays, para-cervical or intra-cervical block, oral dexketoprofen or mefenamic acid have failed to demonstrate significant analgesic efficacy during hysteroscopy. In our study, although oral tramadol could effectively and safely reduce the pain during the procedure due to reduce pre-procedural anxiety and hence the pain perceived during the procedure. The needs for ideal analgesic agents that provide more effective analgesia both during and after hysteroscopy remain.

\section{References}

1. Raju KS. Should outpatient hysteroscopy replace conventional diagnostic dilatation and curettage in gynecologic practice? J Gynecol Surg 1992;8(4):225-230.

2. Nagele F, Lockwood G, Magos AL. Randomized placebo 
controlled trial of mefenamic acid for premedication at outpatient hysteroscopy: a pilot study. $\mathrm{Br} \mathrm{J}$ Obstet Gynaecol 1997 Jul;104(7):842-4

3. Serdar O, Günyeli İ, Yılmaz B, Kelekçi S, Ertaş İE, Kahyaoğlu S, et al. The role of office diagnostic-operative hysteroscopy in postmenopausal women. Gynecol Obstet Reprod Med 2005;11(2):113-16

4. Yang J1, Vollenhoven B. Pain control in outpatient hysteroscopy. Obstet Gynecol Surv 2002;57(10):693-702.

5. De Iaco P, Marabini A, Stefanetti M, Del Vecchio C, Bovicel L. Acceptability and pain of outpatient hysteroscopy. J Am Assoc Gynecol Laparosc 2000 Sep;7(1):71-5.

6. Mercorio F, De Simone R, Landi P, Sarchianaki A, Tessitore G, Nappi C. Oral dexketoprofen for pain treatment during diagnostic hysteroscopy in postmenopausal women. Maturitas 2002 Dec 10;43(4):277-81.

7. Lau WC, Tam WH, Lo WK, Yuen PM. A randomised double-blind placebo-controlled trial of transcervical intrauterine local anaesthesia in outpatient hysteroscopy. BJOG 2000;107(5):610-3.

8. Wong AY, Wong K, Tang LC. Stepwise pain score analysis of the effect of local lignocaine on outpatient hysteroscopy: a randomized, double-blind, placebo-controlled trial. Fertil Steril 2000 Jun;73(6):1234-7.

9. Vercellini P, Colombo A, Mauro F, Oldani S, Bramante T, Crosig- naniPG. Paracervical anaesthesia for outpatient hysteroscopy. Fertil Steril 1994 Nov;62(5):1083-5.

10. Zupi E, Luciano AA, Valli E, Marconi D, Maneschi F, Romanini C. The use of topical anaesthesia in diagnostic hysteroscopy and endometrial biopsy. Fertil Steril 1995; 63(2):414-6.

11. Lewis KS, Han NH. Tramadol: a new centrally acting analgesic. Am J Health Syst Pharm 1997;54(6):643-52.

12. López Rosales C, Cabrera Magaña EN, Solís EJ. Tramadol chlorhydrate in the management of gyneco-obstetric pain. Gynecol Obstet Mex 1997;65:152-4.

13. Floris S, Piras B, Orrù M, Silvetti E, Tusconi A, Melis F, et al. Efficacy of intravenous tramadol treatment for re- ducing pain during office diagnostic hysteroscopy. Fertil Steril 2007;87(1):147-51

14. Wieser F, Kurz C, Wenzl R, Albrecht A, Huber JC, Nagele F. Atraumatic cervical passage at outpatient hysteroscopy. Fertil Steril 1998 Mar; 69(3):549-51.

15. Davies A, Richardson RE, O'Connor H, Baskett TF, Nagele F, Magos AL. Lignocaine aerosol spray in outpatient hysteroscopy: a randomized double-blind placebocontrolled trial. Fertil Steril 1997 Jun;67(6):1019-23.

16. Lau WC, Lo WK, Tam WH, Yuen PM. Paracervical anaesthesia in outpatient hysteroscopy: a randomised doubleblind placebo-controlled trial. Br J Obstet Gynaecol 1999 Apr;106 (4):356-359.

17. Broadbent JAM, Hill NCW, Molnar BG, Rolfe KJ, Magos AL. Randomized placebo control trial to assess the role of intracervical lidocaine in outpatient hysteroscopy. Br J Obstet Gynaecol 1992;99(9):777-780.

18. Johanson N, Cromtom AC, Ramsden SVB. The efficacy of paracervical injection of lidocaine before laser ablation of the cervical transformation zone: A randomized placebo controlled double- blind clinical trial. $\mathrm{Br} \mathrm{J}$ Obstet Gynaecol 1989;96(12):1410-1412.

19. Dogan E, Celiloglu M, Sarihan E, Demir A. Anesthetic effect of intrauterine lidocaine plus naproxen sodium in endometrial biopsy. Obstet Gynecol 2004;103(2):347-51.

20. Nebhinani N, Singh SM, Gupta G. A patient with tramadol dependence and predictable provoked epileptic seizures. Indian J Psychiatry 2013 Jul;55(3):293-4.

21. Zhang H, Liu Z. The investigation of tramadol dependence with no history of substance abuse: a cross-sectional survey of spontaneously reported cases in Guangzhou city, China. Biomed Res Int 2013;2013:283425.

22. Randall C, Crane J. Tramadol deaths in northern Ireland: a review of cases from 1996 to 2012. J Forensic Leg Med 2014;23:32-36.

23. Cha HJ, Song MJ, Lee KW, Kim EJ, Kim YH, Lee Y, et al. Dependence potential of tramadol: behavioral pharmacology in rodents. Biomol Ther (Seoul) 2014;22(6):55862 . 